\title{
The intraday dynamics of bitcoin
}

\author{
Article
}

Accepted Version

Creative Commons: Attribution-Noncommercial-No Derivative Works 4.0

Eross, A., MCGroarty, F., Urquhart, A. and Wolfe, S. (2019) The intraday dynamics of bitcoin. Research in International Business and Finance, 49. pp. 71-81. ISSN 0275-5319 doi: https://doi.org/10.1016/j.ribaf.2019.01.008 Available at https://centaur.reading.ac.uk/81745/

It is advisable to refer to the publisher's version if you intend to cite from the work. See Guidance on citing.

To link to this article DOI: http://dx.doi.org/10.1016/j.ribaf.2019.01.008

Publisher: Elsevier

All outputs in CentAUR are protected by Intellectual Property Rights law, including copyright law. Copyright and IPR is retained by the creators or other copyright holders. Terms and conditions for use of this material are defined in the End User Agreement.

\section{$\underline{\text { www.reading.ac.uk/centaur }}$}

\section{CentAUR}

Central Archive at the University of Reading

Reading's research outputs online 


\title{
The Intraday Dynamics of Bitcoin
}

\begin{abstract}
Bitcoin has received much investor attention in recent years and following this, there has been an explosion of academic studies examining this new financial asset. We contribute to the growing literature of Bitcoin by examining the intraday variables of the leading Bitcoin exchange with the highest information share over 4 years' worth of data to reveal the intraday stylized facts of Bitcoin and how they have developed over time. Employing GMT-timestamped tick data aggregated to the 5-mintuely frequency, we find that Bitcoin returns have increased over time, while trading volume, volatility and liquidity varied substantially over time. We also find that volume increases throughout the day and falls from around 4pm until midnight, which is consistent with the intraday patterns found in currency markets. Realised volatility is fairly consistent throughout the day although it is highest during the opening times of the three major global stock markets. Also liquidity is highest during the opening times of the major global exchanges and the markets tend to be illiquid during the early morning. Finally, we show evidence of the mixture of distribution hypothesis of Clark (1973).
\end{abstract}

Keywords: Bitcoin; Cryptocurrency; Intraday Patterns; Granger causality; Lead-Lag; HighFrequency JEL classification: F30; G02; G15 


\section{Introduction}

Bitcoin is a cryptocurrency which has received a lot of publicity given its innovative features, simplicity, transparency, and its increasing use. Bitcoin was first outlined in a paper by Nakamoto (2008) and since first going online in 2009, has grown dramatically with the Bitcoin user base becoming increasingly global and diversified, as are the currency exchanges. The Bitcoin protocol sends and receives payment information by directly linking individuals who wish to exchange funds without having to involve a third party. Individuals who participate in transactions are anonymous users assigned a public key as an identity and timestamped transactions enabling records to be secure and unchangeable. This method has been seen as superior to transactions involving a third party as costs, such as transaction costs, are removed and trust is replaced by a cryptographic proof which is the chronological timestamp. Therefore the two parties involved in the exchange need not know each other and the security of the transaction is not dependent on the trust provided by a third party executing the exchange. ${ }^{1}$ Unlike fiat currencies that trust the central bank to guarantee the value of the money, with Bitcoin the trust is that the cryptographic proofs provided by the network are correct. Given the recent financial crisis and the bailouts of some European countries and their banks, trust in central banks has diminished and Bitcoin has gained a lot of publicity and surged in value with Bitcoin price increasing by over 21,000\% between January 2012 and March 2017. However, Bitcoin is traded on many exchanges and regulatory issues still influence the Bitcoin exchange rate meaning that different exchanges offer different prices for Bitcoin.

Although the literature of Bitcoin is growing ${ }^{2}$, there lacks a complete understanding of its intraday dynamics. We add to the growing literature on Bitcoin by examining the intraday dynamics (if any)

\footnotetext{
${ }^{1}$ For a discussion on the economics of mining Bitcoin, see Kroll et al (2013).

2 See section 2 for a review of the literature on cryptocurrencies.
} 
of one of the most popular Bitcoin exchanges, Bitstamp. Any intraday stylized facts are very important and may be useful for investors if there is excess liquidity, trading volume or volatility during certain periods of the day. This also have consequences for other cryptocurrency markets and international financial markets and may be of interest to regulators, especially with regards to the price manipulation of Bitcoin recently documented in the literature (Gandal et al 2018) . Specially, we collect GMT-timestamped tick data and aggregate it to the 5-minutely frequency to examine intraday stylized facts of Bitcoin as well as the lead-lag relationship between returns, volume, volatility and liquidity of Bitcoin. Therefore we contribute to the literature in the following ways. Firstly, we add to the growing literature on Bitcoin by examining the intraday seasonality of Bitcoin, which is of high importance to investors and regulators alike. Given the increase in media coverage and trading volume of Bitcoin, an analysis of its intraday behaviour is required. Secondly, we examine the lead-lag relationship between intraday returns, volume, liquidity and volatility of the Bitstamp exchange to determine the relationship between the intraday variables. The relationships between these variables have been examined in some detail in the literature of equities, currencies and commodities, but this is the first on Bitcoin. These intraday dynamics can have huge implications on intraday traders, such as the intraday time-series momentum found in ETFs by Gao et al (2018). If traders know that there is intraday seasonality in in returns, volume, liquidity or volatility, they may be able to take advantage. Thirdly, we study the Granger causality between the intraday Bitcoin variables to examine the direction of any Granger causality between the intraday variables of Bitcoin. Fourthly, we also show how the intraday variables evolve over time, which is of special interest since the behaviour of Bitcoin is ever-changing.

The rest of the paper is organized as follows. Section 2 presents a review of the literature of cryptocurrencies and intraday dynamics, while Section 3 presents the data and methodology employed in this paper. Section 4 presents and discusses the empirical results while Section 5 provides a summary and conclusions. 


\section{Literature Review}

\subsection{Cryptocurrency Literature}

Although initially dominated by literature on the safety, ethical and legal aspects of Bitcoin, recent literature has examined Bitcoin from a financial and economic viewpoint. Cheah and Fry (2015) argue that if Bitcoin were a true unit of account, or a form of store of value, it would not display such volatility expressed by bubbles and crashes. Brandvold et al (2015) employ a multivariate model to study the price discovery process of Bitcoin and find that six Bitcoin exchanges are cointegrated and that Mt.Gox and Bitstamp are the market leaders with the highest information share. They also show that the information share is dynamic and evolves significantly over time. Dwyer (2015) studies the economics of Bitcoin and finds that the average monthly volatility of Bitcoin is higher than for gold or a set of foreign currencies in dollars, but the lowest monthly volatilities for Bitcoin are less than the highest monthly volatility for gold and foreign currencies. Smith (2015) shows that the implied exchange rates of Bitcoin are cointegrated with nominal exchange rates, and there is causality running from the nominal to the implied exchange rates. Dyhrberg (2016a; 2016b) report that Bitcoin has similar hedging capability as gold and the dollar, and as such the currency is an exchange medium and can be used for risk management. Khairuddin et al (2016) study the motivation of Bitcoin users through interviews and find that the main motivations for users are Bitcoin's predicted role in a monetary revolution, users' increased empowerment, and their perception of a real value of Bitcoin currency. Urquhart (2016) finds that Bitcoin is not an efficient market, but in the latter subsample period, some tests suggest that Bitcoin is moving towards efficiency. This has been confirmed in recent studies such as Nadarajah and Chu (2017), Bariviera (2017) and Tiwari et al (2018), which all employ alternative testing procedures and sample periods. Urquhart (2017) shows significant price clustering in Bitcoin while Bouri et al (2017) find that Bitcoin is a poor hedge but suitable for diversification purposes only for major stock market indices, bonds, oil, gold, the commodity index and US dollar. Caporale et 
al (2018) shows significant persistence in cryptocurrency markets while recently Corbet et al (2018a) examine the fundamental drivers of the Bitcoin price and show there are clear periods of bubble behaviour of Bitcoin. Corbet et al (2018b) suggest that Bitcoin has a role in an investor's portfolio, although Bitcoin may contain its own idiosyncratic risks that are difficult to hedge against. Therefore there is some evidence that Bitcoin has some hedging capabilities and diversification benefits while Urquhart (2018) shows that trading volume and volatility are both significant drivers of the attention of Bitcoin. Corbet et al (2018d) show that spot volatility has increased following the appearance of futures contracts, that futures contracts are not an effective hedging instrument, and that price discovery is driven by uninformed investors in the spot market.

Although Bitcoin was created as an alternative currency, it can also be used as an investment and therefore leads to the question whether Bitcoin acts more like a currency or an investment. Recently, the EU ruled that Bitcoin must be treated like a currency and not a commodity for tax purposes (Skatteverket v Hedqvist, EU Press Release 128/15) suggesting that the market is starting to treated Bitcoin like a currency. However academic evidence has suggested that Bitcoin should be treated as an investment with Yernack (2013) arguing that it needs to become more stable so it can reliably serve as a store of value and as a unit of account in commercial markets. They also show that the excess volatility is more consistent with the behaviour of a speculative investment than a currency, and therefore Bitcoins behaviour resembles Internet stocks in the late 1990s. Baur et al (2018) also examine whether Bitcoin is a currency or an investment by analysing the value of Bitcoin's financial characteristics relative to a large number of different assets and whether Bitcoin is used as an investment or currency to pay for goods. They also find that about a third of Bitcoins are held by investors not interested in using them as a currency but as an investment. Therefore they suggest that Bitcoin is mostly used as an investment rather than a currency. Recently, Platanakis et al (2018) show that naïve diversification among cryptocurrencies is as successful as 
optimal diversification while Guesmi et al (2018) show that a short position in the Bitcoin market allows hedging the risk investment for all different financial assets. ${ }^{3}$

\subsection{Intraday Dynamics Literature}

There is a large literature documenting intraday patterns in financial time series such as intraday variations in returns, volatility, volume and liquidity. Some papers on North American markets report that trading activity exhibit a U-shaped pattern (McInish and Wood 1990a; Brock and Kleidon 1992; Hamao and Hasbrouck 1993) while some studies on UK markets report a M-shape where volume is high around the opening of US markets (Ellul et al 2002; Cai et al 2004). Elevated opening and closing returns have also been reflected in the volatility patterns, where a U-shape is reported by Wood et al (1985), McInish and Wood (1990a and 1990b) and Madhavan et al (1997). For currencies, Danielsson and Payne (2001) find an M-shaped volume pattern while Baillie and Bollerslev (1990) find that volatility for major currency pairs peaks twice during the day, when London and New York open, yielding an M-shaped plot. Low and Muthuswamy (1996) find similar peaks in the price change volatility for three major currency pairs when London and New York open and close while McGroarty et al (2009) find an M-shaped intraday pattern for trading volume and volatility of currencies. Ranaldo (2009) and Breedon and Ranaldo (2013) find that currencies tend to depreciate during local trading hours and that this pattern is reflected in the order flow. ap Gwilym and Sutcliffe (1999) divide these observed patterns in intraday trading patterns into two categories. The first, documented by Brock and Kleidon (1992), attributes these patterns to differing trader behaviour at the open and close, while the second, documented by Admati and Pfleiderer (1988), attribute the patterns to the strategic behaviour of informed traders. ${ }^{4}$

\footnotetext{
${ }^{3}$ Corbet et al (2018c) provide a thorough review of the development of the literature among cryptocurrencies.

${ }^{4}$ Since there is no daily open or close in the Bitcoin market, our focus follows Admati and Pfleiderer (1988).
} 
Another stylized fact about financial returns is an asymmetric relationship between returns and volatility, where volatility tends to increase following negative returns and decreases following positive returns. The first one is called the leverage effect, while the second is called the volatility feedback effect which argues that if volatility is priced, an anticipated increase in volatility raises the rate of the return, implying an immediate stock price decline in order to allow for higher future returns (see French et al 1987; Bekaert and Wu 2000). There is also a growing literature reporting stock index returns are negatively correlated with changes in volatility and that the negative relationship is even more pronounced in falling than in rising markets. There have been attempts to explain this relationship, such as Black (1976) and Christie (1982) arguing that positive stock returns increase the market value of the firm's equity and therefore diminish its financial leverage ratio which in turn lowers the volatility of stock returns. Another explanation is that bad news might have different implications for future uncertainty than good news (Glosten et al 1993; Chen and Ghysels 2007). Whether this relationship is return-driven or volatility-driven is open to debate (see Masset and Wallemier 2010) as most of the recent studies show evidence of both. ${ }^{5}$ Clark's (1973) mixture of distributions hypothesis (MDH) argues that volatility and volume move together in response to common but not directly observable external stimuli, which is associated with public information. This is supported by Copeland (1976) and Jennings et al (1981) who show that traders receive a signal ahead of the market and trade on it, thereby creating volume and moving price (volatility). Intraday stylized facts have also been found in precious metals, with Batten et al 2017 documenting strong periodicity in intraday variables linked to the opening and closing of major stock markets around the world.

\section{Data and Variables of Interest}

\footnotetext{
${ }^{5}$ Bollerslev et al (2006), Giot (2005) and Dufour et al (2012) report evidence of a return-driven relationship while Bekaert and Wu (2000) and Dennis et al (2006) find evidence of a volatility-driven relationship.
} 
In this section, we present the data employed in this study as well as the calculation of the variables utilised to examine the high-frequency dynamics of Bitcoin.

\subsection{Data}

The data for this paper is downloaded from www.Bitcoincharts.com, which provides the complete historic trade data of various Bitcoin exchanges. It provides the unixtime, price and volume of various Bitcoin exchanges. We study the Bitstamp exchange at the 5-minute frequency to examine the intraday dynamics of Bitcoin returns, volume, volatility and liquidity. The Bitstamp exchange is one of the largest exchanges denoted in US dollars and as Brandvold et al (2015) note, is the market leader with the highest information share along with Mt.Gox until its demise. ${ }^{6}$ We choose the 5-minute frequency since at any higher frequency the data was often missing due to low liquidity which may lead to unreliable and spurious results. Also as Anderson (2000) points out, the 5-minute frequency is the best compromise between having enough observations to examine the intraday dynamics while also at the same time having enough data to avoid noise issues.

In order to generate 5-minutely intervals from the data, we aggregate the data into 5-minutely data so that we obtain high/low/open/close prices for each 5-minute period. Our sample period runs from $1^{\text {st }}$ January 2014 to $31^{\text {st }}$ December 2017 and is chosen since before this period, high frequency data was infrequent and spurious. Only a handful of 5-minutely data is missing over our complete sample period, therefore enabling a complete examination of the intraday dynamics of Bitcoin. ${ }^{7}$ The Bitstamp exchange trades 24-hours a day and anyone throughout the world can trade Bitcoin. An issue faced is what time zone to select since the data is provided in unixtime. Following Ranaldo (2009), we account for differences in daylight savings times by expressing time in terms

\footnotetext{
${ }^{6}$ Mt.Gox went bankrupt on $26^{\text {th }}$ February 2014 and so is not included in our study. Mt.Gox was the largest exchange before its bankruptcy. BTC-e is also studied and reports similar results. We do not report the results to conserve space but are available from the authors upon request.

${ }^{7}$ Bitstamp has suffered some outages related to Distributed Denial service attacks and therefore no data is obtained during these periods. However, these periods are very infrequent and do not last long (Millet, 2014).
} 
of Greenwich Mean Time (GMT). Figure 1 shows the time-series graph of the price and volume of Bitcoin throughout our sample period. The price of Bitcoin has generally increased during our sample period and especially since August 2015. Volume has stayed fairly constant, except for a few sharp jumps in the magnitude of trading activity.

\subsection{Variables of Interest}

The variables of interest in this paper are returns, volume, liquidity and volatility. We calculate log returns as;

$$
r_{t, d}=\left(\operatorname{In} P_{t, d}-\operatorname{In} P_{t, d-1}\right) \times 100
$$

where $r_{t, d}$ is the return for the intraday period $d$ on trading day $t$ and $P_{t, d}$ is the price for the intraday period $d$ on trading day $t$. We employ the popular realised volatility (RV) as our measure of volatility such that ${ }^{8}$;

$$
R V=\operatorname{In}\left(P_{t} / P_{t-1}\right)^{2}
$$

We also study the trading volume of Bitcoin, with the variable provided by the data source and we aggregate up the tick level data to gain 5-minute measures of trading volume. Our last variable of interest is liquidity, where we employ the Amihud measure which captures price changes per unit of dollar volume (Amihud 2002). Higher Amihud values indicate more illiquidity and is calculated such that:

$$
\text { Amihud }=\frac{\left|r_{t}\right|}{\text { Volume }_{t}}
$$

\footnotetext{
${ }^{8}$ We do not include non-parametric volatility measures as these measures have very different properties to the other variables employed in this study.
} 
Where $\left|r_{t}\right|$ is the absolute returns at time $t$ and Volume $_{t}$ is the dollar volume on day $t$. The Amihud measure is scaled by $10^{3}$ for practical application. Therefore, a higher level of the Amihud measure indicates more illiquidity in the Bitcoin market.

\subsection{Methodology}

In this paper we study the intraday dynamics of Bitcoin, where we initially examine the intraday patterns through graphical analysis. Although the graphical analysis is widely used in the literature, we also employ a simple regression analysis to examine statistically the difference in the intraday variables. Specifically, we follow Khademalomoom and Narayan (2018) and run a simple GARCH regression to ensure our test is free from heterocedasticity such that:

$$
\begin{gathered}
R_{t}=\sum_{i=1}^{288} \beta_{i} D_{i}+\sum_{j=1}^{n} \beta_{j} R_{t-1}+\varepsilon_{t} \\
\sigma_{t}^{2}=\omega+\theta \varepsilon_{t-1}^{2}+\lambda \sigma_{t-1}^{2}
\end{gathered}
$$

Where $R_{t}$ is the returns and $D_{i}$ is a dummy variable for the $\mathrm{i}^{\text {th }}$ interval of a day. We lag value of the returns is included to control for autocorrelation. We repeat this analysis for all of our variables of interest.

We also employ the Granger causality test to study whether there is significant causality between the intraday variables of Bitcoin. The Granger causality test is popular way to test if there is any temporal statistical relationship with a predictive value between two time series (Granger 1969). This test indicates any possible short-run predictive interrelationships among the series. If we consider two series $x_{t}$ and $y_{t}$, then we estimate the following equations: 


$$
\begin{aligned}
& \Delta x_{t}=\beta_{0}+\sum_{i=1}^{n} \beta_{1 i} \Delta x_{t-1}+\sum_{i=1}^{m} \beta_{2 i} \Delta y_{t-1}+\varepsilon_{1 t} \\
& \Delta y_{t}=\delta_{0}+\sum_{i=1}^{n} \delta_{1 i} \Delta y_{t-1}+\sum_{i=1}^{m} \delta_{2 i} \Delta x_{t-1}+\varepsilon_{1 t}
\end{aligned}
$$

After estimating the Granger-causality test, we run an F-test for joint insignificance of the coefficients. Assuming the null hypothesis that $x_{t}$ does not Granger cause $y_{t}$, a rejection of the null hypothesis shows a presence of Granger causality.

\section{Empirical Results}

This section provides the descriptive statistics and the empirical results for intraday patterns of Bitcoin as well as the correlation and lead-lag relationships between the intraday variables. ${ }^{9}$

\subsection{Descriptive Statistics}

Table 1 reports the descriptive statistics for Bitstamp for the four subsample years employed in this study. We can see that that the mean return in 2014 was negative, since then, each year has documented a continued increase in the mean 5-minute returns. For instance in 2017, the 5minute mean return was 0.0025 , an over $700 \%$ increase in mean return from the 0.0003 mean return in 2015. Since 2015, returns have negative skewness and excess kurtosis, indicating a leptokurtic distribution. The volume of trading descriptive statistics show that the mean trading volume is fairly consistent in years 2014, 2015 and 2017 at 48.65, 54.58 and 44.81 respectively. But the mean trading volume in 2016 is 19.50 which is substantially less than the other years indicating

\footnotetext{
${ }^{9}$ We only report the patterns for variables that show a discernible pattern to conserve space. However all intraday patterns are available upon request from the corresponding author.
} 
that Bitcoin did not attract that much trading attention from investors in 2016 compared to the other three years examined. The descriptive statistics of the RV show that the mean RV was highest in 2017 and lowest in 2016, which is consistent with the lower trading volume in 2016. Our measure of liquidity shows that liquidity has varied over time, but has become substantially more liquid in the 2017 compared to the previous three years. Therefore our descriptive statistics show that there is quite a large variation in the behaviour the Bitcoin variables during 2014 to 2017. To examine this further, we study the intraday behaviour of these variables in the following section.

\subsection{Intraday Patterns}

Figure 2 presents the intraday mean volume and we see that volume is fairly low until 07:00 when trading volume increases until 10:30, therefore suggesting an inverted U-shape for all four-sample periods studied. Volume again peaks at 14:00 and then gradually decreases over the rest of the day. This pattern is consistent with the idea that volume of certain currency markets increases when European and North American markets open. This suggests that European and North American investors are the main drivers of the volume traded of USD denominated Bitcoin. ${ }^{10}$ Consistent with our previous analysis, the volume of trading during 2016 is substantially less than the other years studied. Intraday RV is shown in Figure 3 and we can see that it is at its highest from 07:00 and declines after 18:00, again indicating that the variation in Bitcoin is at its strongest during the open periods of European and North American markets. These intraday patterns for volume and volatility are broadly reminiscent of patterns observed in the foreign exchange market and are consistent with the idea that volume and volatility are correlated. Figure 4 shows the intraday liquidity over time and we show that the liquidity measure is highest during the beginning of the day, indicating higher illiquidity in the market during this time period. Liquidity is highest from 10:00 and throughout the rest of the day indicating that liquidity is highest when all three of

\footnotetext{
10 Although investors can trade outside the usual trading hours of stock markets, consistent with the literature we assume that they will conduct most of their trading during normal stock market trading hours.
} 
the main stock exchanges are open. Also, as expected liquidity has generally improved over time, as our liquidity measure gets smaller for each time period studied.

All the intraday patterns are consistent across the sample periods, indicating that there hasn't been a dramatic change in the intraday behaviour of Bitcoin over the sample periods. In the next section, we examine the relationship between the intraday variables over our subsample periods.

\subsection{Correlation Matrix}

In Table 2, we examine the correlation matrix for Bitcoin to determine how the intraday variables are related to each other for the four years examined. Our correlation matrix reports very small correlation coefficients, indicating that the relationships between our variables of interest are not substantial. We consistently find that returns and volume are negatively correlated, indicated that when returns are higher (lower), the trading volume of returns is lower (higher), although this negative correlation is quite small in magnitude. Returns also have a positive relationship with RV only in the 2014 period, and a negative relationship in the 2015, 2016 and 2017 periods, again the relationship is not large in magnitude. RV and volume have a positive relationship in all four years which is expected. Liquidity is negatively correlated with volume in each sample period, although there appears to be little or no evidence of any correlation between liquidity and the other variables examined in this study.

\subsection{Lead-Lag Relationships}

In the previous section, we find that intraday returns, volume, volatility and liquidity of Bitcoin may be correlated with one another. We therefore examine the origins of these relationships to determine which variable is driving the relationships. We examine the cross-correlation coefficient where one variable is at time interval $t$ and the other at time interval $t+j$, where $j \in\{-10, \ldots$, 
$10\} .{ }^{11,12}$ Figure 5 reports the cross-correlation between Bitcoin returns and volume and shows that the correlation is negative for a number of lagged volumes. This suggests that returns may be systematically related to the preceding volume. We also find that returns are correlated with volume in the proceeding 5 -minutes, with the first two leads not near zero. This suggests a bilateral lead-lag relationship between returns and volume. Figure 6 shows the correlation coefficient is negative at a number of lagged $\mathrm{RV}$, while returns are correlated with $\mathrm{RV}$ in the preceding couple of leads, indicating a bilateral lead-lag relationship between returns and RV. Figure 7 presents a bilateral relationship between Bitcoin volume and RV which seems symmetrical in magnitude indicating a symmetric positive correlation between Bitcoin volume and RV. This is clear across all four subsample periods indicating the strength and consistency of this relationship. Finally, Figure 8 reports the cross-correlation between volume of trading and liquidity and shows a symmetric negative correlation that decreases in magnitude as the number of lags increases. This relationship is strongest for the 2016 subsample, with little or no pattern whatsoever for the 2015 subsample.

Therefore our results suggest that there is strong evidence of some lead-lag relationships between the intraday variables of Bitcoin. However, one issue is that the cross-correlation analysis excludes partial cross-correlations (Masset and Wallmeier 2010). It could be the case that correlations computed for lags greater than 2 are completely due to the correlation at lag $=1$. A more detailed study is therefore necessary to identify causality and the number of lagged intraday variables which have an impact on other intraday variables of Bitcoin.

\subsection{Granger Causality}

\footnotetext{
11 The lead-lag relationships at any higher lags are insignificant but are available upon request from the corresponding author.

${ }^{12}$ We only report cross-correlations for variables with a discernible pattern. Some relationships offer no pattern and therefore are not included to conserve space but are available upon request from the corresponding author.
} 
The Granger causality test is implemented to determine the causality between our intraday variables. Table 3 summarises the results of the Wald F-test for the full sample period for up to ten lags $(p=10) .{ }^{13}$ We report the F-statistic and their significance and find bi-directional causality between returns, RV and volume. That, is, each relationship studied rejects the null hypothesis of no causality indicating that one past variable does contribute to the explanation of the current variable. Although all are significant at least at the 5\% level, some relationships are stronger than others. For instance, the relationship between RV and volume in 2014 only generates a F-stat of 13.17, but the same relationship in 2017 is 746.02 . However the liquidity results indicating that there is no causality between returns and liquidity, as well as between RV and liquidity. In each subsample period, the F-statistic is insignificant indicating no causality between these variables. However there is granger causality between volume and liquidity in the 2014 and 2017 subsamples, and bidirectional causality between volume and liquidity in the 2016 subsample. Therefore this indicates that the relationship between these intraday variables does vary over time and investors should be wary of such changes.

\section{Summary and Conclusions}

It is well known that equity markets and currencies exhibit intraday patterns and that there are relationships between intraday returns, volume, volatility and liquidity. Bitcoin is a relatively new financial instrument which has created considerable debate in the media as well as the academic literature. However, there is relatively little known about Bitcoin from an investor and academic viewpoint. Therefore we add to the sparse literature by examining the intraday stylized facts of Bitcoin volume, realised volatility and liquidity throughout the day as well as the dynamics between these variables. We aggregate tick data to the 5-minutely frequency of the Bitstamp exchange and study the behaviour of Bitcoin variables from 2014-2017 in 4 equally-sized sample periods. We

\footnotetext{
13 All variables are noted to be stationary through the Augmented Dickey-Fuller unit root test and the KPSS test for stationarity. Results of these tests are available upon request from the corresponding author.
} 
find that Bitcoin returns have increased over time, while trading volume and volatility have gradually decreased. We also find that volume increases throughout the day and falls from around $2 \mathrm{pm}$ until midnight, which is consistent with the intraday patterns found in currency markets. Realised volatility is fairly consistent throughout the day although it is highest during the opening times of the three major global stock markets. Also liquidity is highest during the opening times of the major global exchanges and the markets are illiquid during the early morning.

We also examine the relationships between our variables and find a significant negative relationship between returns and volatility, which is consistent with the literature. However, we find that this relationship is not return- or volatility-driven but is a bilateral relationship according to Granger causality. We find a significant positive relationship between volatility and volume which is consistent with the mixture of distributions hypothesis (MDH) by Clark (1973) that argues that volatility and volume move together and that this relationship is bilateral according to the Granger causality test. However liquidity is not related to returns or RV and there is no Granger causality between these variables in any of the sample periods examined.

Therefore our paper is the first to examine the intraday dynamics of Bitcoin variables at the 5minute frequency. We show that the relationship between and the intraday behaviour of these intraday variables do vary over time indicating that researchers should be careful to guard against this when examining any aspects of this popular cryptocurrency. 


\section{References}

Admati, A. R., Pfleiderer, P. (1988). A theory of intraday patterns: volume and price variability. Review of Financial Studies, 1, 3-40.

Ali, R., Barrdear, J., Clews, R., Southgate, J. (2014). The economics of digital currencies. Bank of England Quarterly Bulletin, Q3, 1-11.

Amihud, Y. (2002). Illiquidity and stock returns: cross-section and time-series effects. Journal of Financial Markets, 5(1), 31-56.

Anderson, T. G. (2000). Some reflections on analysis of high-frequency data. Journal of Business, Economics and Statistics, 18, 146-153.

Angel, J., J., McCabe, D. (2015). The ethics of payments: paper, plastic, or Bitcoin? Journal of Business Ethics, 132, 603-611.

ap Gwilym, O., Sutcliffe, C. (1999). High-frequency financial market data: sources, applications and market microstructure. Risk Books.

Baillie, R. T., Bollerslev, T. (1990). Intraday and inter-market volatility in foreign exchange rates. Review of Economic Studies, 58, 565-585.

Bariviera, A. F. (2017). The inefficiency of Bitcoin revisited: A dynamic approach. Economics Letters, $161,1-4$.

Batten, J., Lucey, B., McGroarty, F., Peat, M., Urquhart, A. (2017). Stylized facts of intraday precious metals. PLOS ONE, 12(4): e0174232.

Baur, D. G., Hong, K., Lee, A. D. (2018). Bitcoin: Currency or Investment? Journal of International Financial Markets, Institutions and Money, forthcoming.

Bekaert, G., Wu, G. (2000). Asymmetric volatility and risk in equity markets. Review of Financial Studies, 13, 1-42.

Black, F. (1976). Studies of stock price volatility changes, Proceedings of the meetings of the American Statistical Association, Business and Economics Section, Chicago, 177-181.

Bollerslev, T., Litvinova, J., Tauchen, G. (2006). Leverage and volatility feedback efforts in highfrequency data. Journal of Financial Econometrics, 4, 353-384.

Bouri, E., Molnár, P., Azzi, G, Roubaud, D., Hagfors, L. I. (2017). On the hedge and safe haven properties of Bitcoin: Is it really more than a diversifier? Finance Research Letters, 20, 192198.

Brandvold, M., Molnár, P., Vagstad, K., Valstad, O. C. A. (2015). Price discovery on Bitcoin exchanges. Journal of International Financial Markets, Institutions and Money, 36, 18-35.

Breedon, F., Ranaldo, A. (2013). Intraday Patterns in FX Returns and Order Flow. Journal of Money, Credit and Banking, 45(5), 953-965.

Brock, W. A., Kleidon, A. W. (1992). Periodic market closure and trading volume: A model of intra-day bids and asks. Journal of Economic Dynamics and Control, 16, 451-489.

Cai, C. X., Hudson, R., Keasey, K. (2004). Intraday bid-ask spreads, trading volume and volatility: Recent empirical evidence from the London Stock Exchange. Journal of Business Finance and Accounting, 31, 647-676.

Caporale, G. M., Gils-Alana, L., Plastun, A. (2018). Persistence in the cryptocurrency market. Research in International Business and Finance, forthcoming.

Cheah, E-T., Fry J. (2015). Speculative bubbles in Bitcoin markets? An empirical investigation into the fundamental value of Bitcoin. Economics Letters, 130, 32-36.

Chen, X., Ghysels, E. (2007). News - good or bad - and its impact over multiple horizons. Review of Financial Studies, 42, 46-81.

Christie, A. (1982). The stochastic behaviour of common stock variances: value, leverage and interest rate effects. Journal of Financial Economics, 10, 407-432.

Clark, P. K. (1973). A subordinated stochastic model with finite variance for speculative prices. Econometrica, 41, 135-155.

Copeland, T. (1976). A model of asset trading under the assumption of sequential information arrival. Journal of Finance, 31, 1149-1168. 
Corbet, S., Lucey, B., Yarovaya, L. (2018a). Datestamping the Bitcoin and Ethereum bubbles. Finance Research Letters, forthcoming.

Corbet, S., Meegan, A., Larkin, C., Lucey, B., Yarovaya, L. (2018b). Exploring the Dynamic Relationships between Cryptocurrencies and Other Financial Assets. Economics Letters, 165, 28-34.

Corbet, S., Lucey, B., Urquhart, A., Yarovaya, L. (2018c). Cryptocurrencies as a Financial Asset: A Systematic Analysis, International Review of Financial Analysis, forthcoming.

Corbet S., Lucey, B., Peat, M., Vigne, S. (2018d). Bitcoin Futures - What use are they? Economics Letters, 172, 23-27.

Danielsson, J. Payne, R. (2001). Measuring and explaining liquidity on an electronic limit order book: evidence from Reuters D2000-2. EFA 2001 Barcelona Meetings.

Dennis, P., Mayhew, S., Stivers, C. (2006). Stock returns, implied volatility innovations, and the asymmetric volatility phenomenon. Journal of Financial and Quantitative Analysis, 41, 381-406.

Dufour, J., Garcia, R., Taamouti, A. (2012). Measuring High-Frequency Causality Between Returns, Realized Volatility and Implied Volatility. Journal of Financial Econometrics, 10, 124163.

Dwyer, G. P. (2015). The economics of Bitcoin and similar private digital currencies. Journal of Financial Stability, 17, 81-91.

Dyhrberg, A. H. (2016a). Bitcoin, gold and the dollar - a GARCH volatility analysis. Finance Research Letters, 16, 85-92.

Dyhrberg, A. H. (2016b). Hedging capabilities of Bitcoin. Is it the virtual gold? Finance Research Letters, 16, 139-144.

Ellul, A., Shin, H. S., Tonks, I. (2002). Towards deep and liquid markets: Lessons from open and close at the London Stock Exchange. LSE Financial Markets Group Working Paper.

European Central Bank (2012). Virtual currency schemes. Preprint. https://www.ecb.europa.eu/pub/pdf/other/virtualcurrencyschemes201210en.pdf.

French, K., Schwert, G., Stambaugh, R. (1987). Expected stock returns and volatility. Journal of Financial Economics, 19, 3-29.

Gandal, N., Hamrick, J. T., Moore, T., Oberman, T. (2018). Price manipulation in the Bitcoin ecosystem. Journal of Monetary Economics, 95, 86-96.

Gao, L., Han, Y., Li, S. Z., Zhou, G. (2018). Market intraday momentum. Journal of Financial Economics, 129(2), 394-414.

Giot, P. (2005). On the relationships between implied volatility indices and stock index returns. Journal of Portfolio Management, 26, 12-17.

Glosten, L., Jaganathan, R., Runkle, D. (1993). On the relation between the expected value and the volatility of the nominal excess return on the stocks. Journal of Finance, 48, 1779-1801.

Granger, C. W. J. (1969). Investigating causal relations by econometric models and cross-spectral methods. Econometrica, 37(3), 424-438.

Guesmi, K., Saadi, S., Abid, I., Ftiti, Z. (2018). Portfolio diversification with virtual currency: Evidence from bitcoin. International Review of Financial Analysis, forthcoming.

Hamao, Y., Hasbrouck, J. (1993). Securities trading in the absence of dealers: Trades and quotes on the Tokyo Stock Exchange. Review of Financial Studies, 8, 849-878.

Jennings, R., Starks, L., Fellingham, J. (1981). An equilibrium model of asset trading with sequential information arrival. Journal of Finance, 36, 143-161.

Khademalomoom, S., Narayan, P. K. (2018). Intraday effects of the currency market. Journal of International Financial Markets, Institutions and Money, forthcoming.

Khairuddin, I. E., Sas, C., Clinch, S., Davies, N. (2016). Exploring Motivations among Bitcoin Users. CHI 2016, San Jose, CA, USA.

Kroll, J. A., Davey, I. C., Felton, E. W. (2013). The economics of Bitcoin mining, or Bitcoin in the presence of adversaries. In: Proceedings of WEIS, vol. 2013.

Low, A. H. W., Muthuswamy, J. (1996). Information flows in high frequency exchange rates. In: 
Dunis, C (Ed.), Forecasting Financial Markets: Exchange Rates, Interest Rates and Asset Management. John Wiley, pp. 3-32.

Madhavan, A., Richardson, M., Roomans, M. (1997). Why do security prices change? A transactions level analysis of NYSE stocks. Review of Financial Studies, 10, 1035-1064.

Masset, P., Wallmeier, M. (2010). A High-Frequency Investigation of the Interaction between Volatility and DAX Returns. European Financial Management, 16(3), 327-344.

McGroarty, F., ap Gwilym, O., Thomas, S. (2009). The role of private information in return volatility, bid-ask spreads and price levels in the foreign exchange market. Journal of International Financial Markets, Institutions and Money, 19, 387-401.

McInish, T. H., Wood, R. A. (1990a). An analysis of transactions data for the Toronto Stock Exchange. Journal of Banking and Finance, 14, 441-458.

McInish, T. H., Wood, R. A. (1990b). A transaction data analysis of the variability of common stock returns during 1980-1984. Journal of Banking and Finance, 14, 99-112.

Millet, J. (2014). Bitstamp reports DDOS Attack Against Their Server. NewsBTC. Available at http://www.newsbtc.com/2014/04/13/Bitstamp-reports-ddos-attack-server.

Nakamoto, S. (2008). Bitcoin: A Peer-to-Peer Electronic Cash System.

Nadarajah, S., Chu, J. (2017), On the inefficiency of Bitcoin. Economics Letters, 150, 6-9.

Plasaras, N. (2013). Regulating digital currencies: Bringing Bitcoin within the reach of the IMF. Chicago Journal of International Law, 14, 377-407.

Platanakis, E., Sutcliffe, C., Urquhart, A. (2018). Optimal vs naïve diversification in cryptocurrencies. Economics Letters, 171, 93-96.

Ranaldo, A. (2009). Segmentation and time-of-the-day patterns in foreign exchange markets. Journal of Banking and Finance, 33, 2199-2206.

Skatteverket v Hedqvist (2015) Court of Justice of the European Union Press Release No 128/15. The exchange of traditional currencies of units of the 'bitcoin' virtual currency is exempt from VAT. Available at http://curia.europa.eu/joms/upload/docs/application/pdf/201510/cp150128en.pdf.

Smith, J. B. (2015). An analysis of Bitcoin exchange rates. Available at SSRN 2493797.

Tiwari, A. K., Jana, R. K., Das, D., Roubaud, D. (2018). Informational efficiency of Bitcoin - An extension. Economics Letters, 163, 106-109.

Urquhart, A. (2016). The Inefficiency of Bitcoin. Economics Letters, 148, 80-82.

Urquhart, A. (2017). Price clustering in Bitcoin. Economics Letters, 159, 145-148.

Urquhart, A. (2018). What causes the attention of Bitcoin? Economics Letters, 166, 40-44.

White, L. (2014). The market for cryptocurrencies. Preprint. Found at http://object.cato.org/sites/cato.org/files/serials/files/cato-journal/2015/5/cj-v35n213.pdf.

Wood, A. R., McInish, H. T., Ord, K. (1985). An investigation of transactions data for NYSE stocks. Journal of Finance, 40, 723-739.

Yermack, D. (2013). Is Bitcoin a Real Currency? An Economic Appraisal. NBER Working Paper 19747. Available at http:// www.nber.org/papers/w19747. 
Table 1: Descriptive statistics of Bitstamp at the 5-minute frequency.

\begin{tabular}{|c|c|c|c|c|c|}
\hline & & 2014 & 2015 & 2016 & 2017 \\
\hline & Mean & -0.0008 & 0.0003 & 0.0008 & 0.0025 \\
\hline & Std.Dev & 0.3561 & 0.2927 & 0.1945 & 0.3629 \\
\hline \multirow[t]{6}{*}{ Returns } & Min & -9.2264 & -20.7557 & -6.3521 & -15.5402 \\
\hline & Max & 9.5424 & 8.4865 & 7.3254 & 7.3727 \\
\hline & Skewness & 0.2661 & -4.6221 & -0.7474 & -1.2290 \\
\hline & Kurtosis & 53.5943 & 357.5846 & 60.3714 & 60.3862 \\
\hline & Mean & 48.6486 & 54.5769 & 19.4968 & 44.8111 \\
\hline & Std.Dev & 134.3532 & 130.8089 & 50.1527 & 71.4456 \\
\hline \multirow[t]{6}{*}{ Volume } & Min & 0.0000 & 0.0000 & 0.0000 & 0.0000 \\
\hline & Max & 7682.5500 & 7070.5600 & 2898.4900 & 5051.4200 \\
\hline & Skewness & 13.3897 & 8.8461 & 11.5523 & 9.1525 \\
\hline & Kurtosis & 400.4985 & 183.9044 & 306.4745 & 313.5805 \\
\hline & Mean & 0.1268 & 0.0857 & 0.0378 & 0.1317 \\
\hline & Std.Dev & 0.9194 & 1.6179 & 0.2916 & 1.0145 \\
\hline \multirow[t]{6}{*}{ RV } & Min & 0.0000 & 0.0000 & 0.0000 & 0.0000 \\
\hline & Max & 219.2567 & 430.7988 & 53.6622 & 241.4973 \\
\hline & Skewness & 145.0034 & 202.3867 & 105.2641 & 141.0538 \\
\hline & Kurtosis & 32134.5442 & 50942.4313 & 16113.3048 & 31211.6666 \\
\hline & Mean & 0.3503 & 0.2303 & 0.2860 & 0.0231 \\
\hline & Std.Dev & 5.9741 & 15.7227 & 1.9310 & 0.3592 \\
\hline \multirow[t]{4}{*}{ Amihud } & Min & 0.0000 & 0.0000 & 0.0000 & 0.0000 \\
\hline & Max & 1027.1115 & 4986.8202 & 69.5752 & 37.9397 \\
\hline & Skewness & 83.4879 & 315.1459 & 16.3719 & 57.4792 \\
\hline & Kurtosis & 10746.3641 & 99948.1599 & 353.5168 & 4327.8637 \\
\hline
\end{tabular}


Table 2: Correlation matrix between the variables of Bitstamp.

\begin{tabular}{cccccc}
\hline \multirow{4}{*}{2014} & Returns & Volume & RV & Amihud \\
\hline \multirow{8}{*}{2015} & Returns & & -0.08 & 0.04 & 0.01 \\
& Volume & -0.08 & & 0.41 & -0.02 \\
& RV & 0.04 & 0.41 & & 0.00 \\
& Amihud & 0.01 & -0.02 & 0.00 & \\
\hline \multirow{2}{*}{2016} & Returns & & -0.11 & -0.24 & 0.00 \\
& Volume & -0.11 & & 0.32 & -0.01 \\
& RV & -0.24 & 0.32 & & 0.00 \\
& Amihud & 0.00 & -0.01 & 0.00 & \\
\hline \multirow{2}{*}{2017} & Returns & & -0.07 & -0.10 & 0.00 \\
& Volume & -0.07 & & 0.37 & -0.06 \\
& RV & -0.10 & 0.37 & & 0.01 \\
& Amihud & 0.00 & -0.06 & 0.01 & \\
& Returns & & -0.11 & -0.16 & 0.00 \\
& Volume & -0.11 & & 0.39 & -0.04 \\
& RV & -0.16 & 0.39 & & 0.00 \\
\hline
\end{tabular}


Table 3: The Granger causality results along with the F-statistics. ***, **, * indicate significance at $1 \%, 5 \%$ and $10 \%$ respectively.

\begin{tabular}{|c|c|c|c|c|}
\hline & & F-stat & & F-stat \\
\hline \multirow{6}{*}{2014} & Returns - Volume & $17.39 * * *$ & Volume - Returns & $17.52^{* * *}$ \\
\hline & Returns - RV & $143.87 * * *$ & RV - Returns & $61.85^{* * *}$ \\
\hline & RV - Volume & $13.17 * * *$ & Volume - RV & $364.9 * * *$ \\
\hline & Returns - Liquidity & 1.11 & Liquidity - Returns & 1.35 \\
\hline & RV - Liquidity & 0.62 & Liquidity - RV & 0.28 \\
\hline & Volume - Liquidity & $3.56^{* * *}$ & Liquidity - Volume & 0.74 \\
\hline \multirow{6}{*}{2015} & Returns - Volume & $37.98^{* * *}$ & Volume - Returns & $32.97 * * *$ \\
\hline & Returns - RV & $32.67 * * *$ & RV - Returns & $326.01 * * *$ \\
\hline & RV - Volume & $57.37 * * *$ & Volume - RV & $19.45^{* * *}$ \\
\hline & Returns - Liquidity & 1.09 & Liquidity - Returns & 0.67 \\
\hline & RV - Liquidity & 0.03 & Liquidity - RV & 0.01 \\
\hline & Volume - Liquidity & 0.92 & Liquidity - Volume & 0.53 \\
\hline \multirow{6}{*}{2016} & Returns - Volume & $35.45^{* * *}$ & Volume - Returns & $12.86^{* * *}$ \\
\hline & Returns - RV & $93.44 * * *$ & RV - Returns & $79.46^{* * *}$ \\
\hline & RV - Volume & $82.24 * * *$ & Volume - RV & $143.74 * * *$ \\
\hline & Returns - Liquidity & $1.86^{* *}$ & Liquidity - Returns & $1.73^{*}$ \\
\hline & RV - Liquidity & 0.53 & Liquidity - RV & 0.79 \\
\hline & Volume - Liquidity & $8.67 * * *$ & Liquidity - Volume & $3.34 * * *$ \\
\hline \multirow{6}{*}{2017} & Returns - Volume & $121.48^{* * *}$ & Volume - Returns & $27.54 * * *$ \\
\hline & Returns - RV & $35.29 * * *$ & RV - Returns & $46.76^{* * *}$ \\
\hline & RV - Volume & $746.02^{* * *}$ & Volume - RV & $112.94 * * *$ \\
\hline & Returns - Liquidity & 0.15 & Liquidity - Returns & 0.06 \\
\hline & RV - Liquidity & 0.25 & Liquidity - RV & 0.22 \\
\hline & Volume - Liquidity & $3.85^{* * *}$ & Liquidity - Volume & 1.09 \\
\hline
\end{tabular}


Figure 1: Time-series graph of the price of Bitstamp on the primary y-axis and volume on the secondary y-axis.

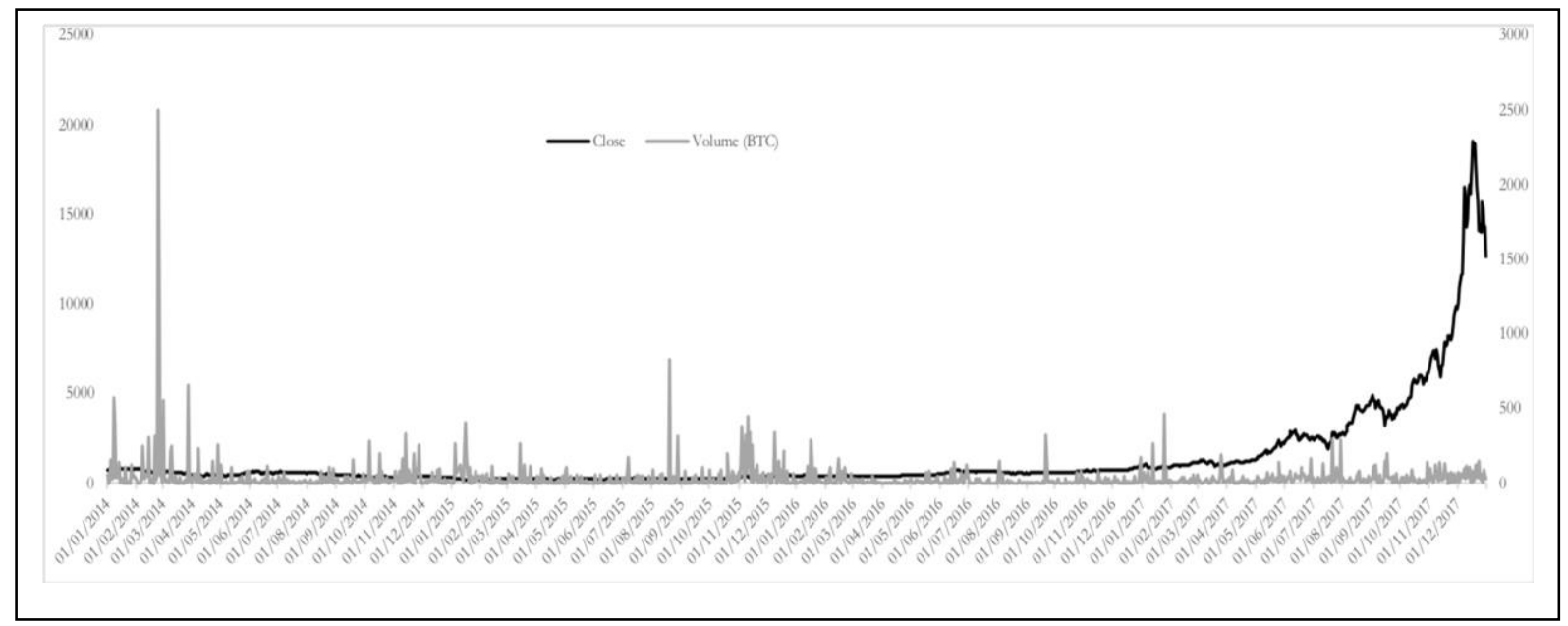


Figure 2: Intraday mean volume of Bitstamp over the four sample periods.

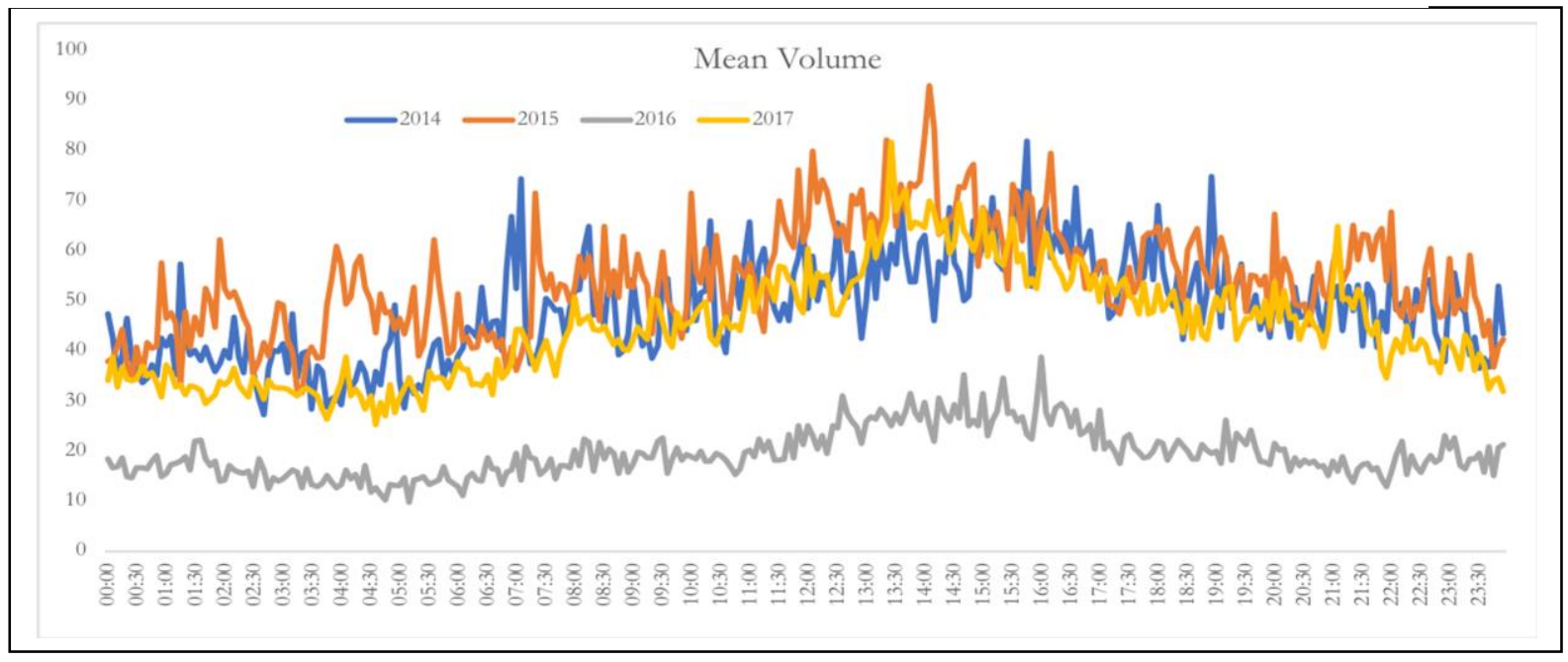

Figure 3: Intraday mean RV of Bitstamp over the four sample periods.

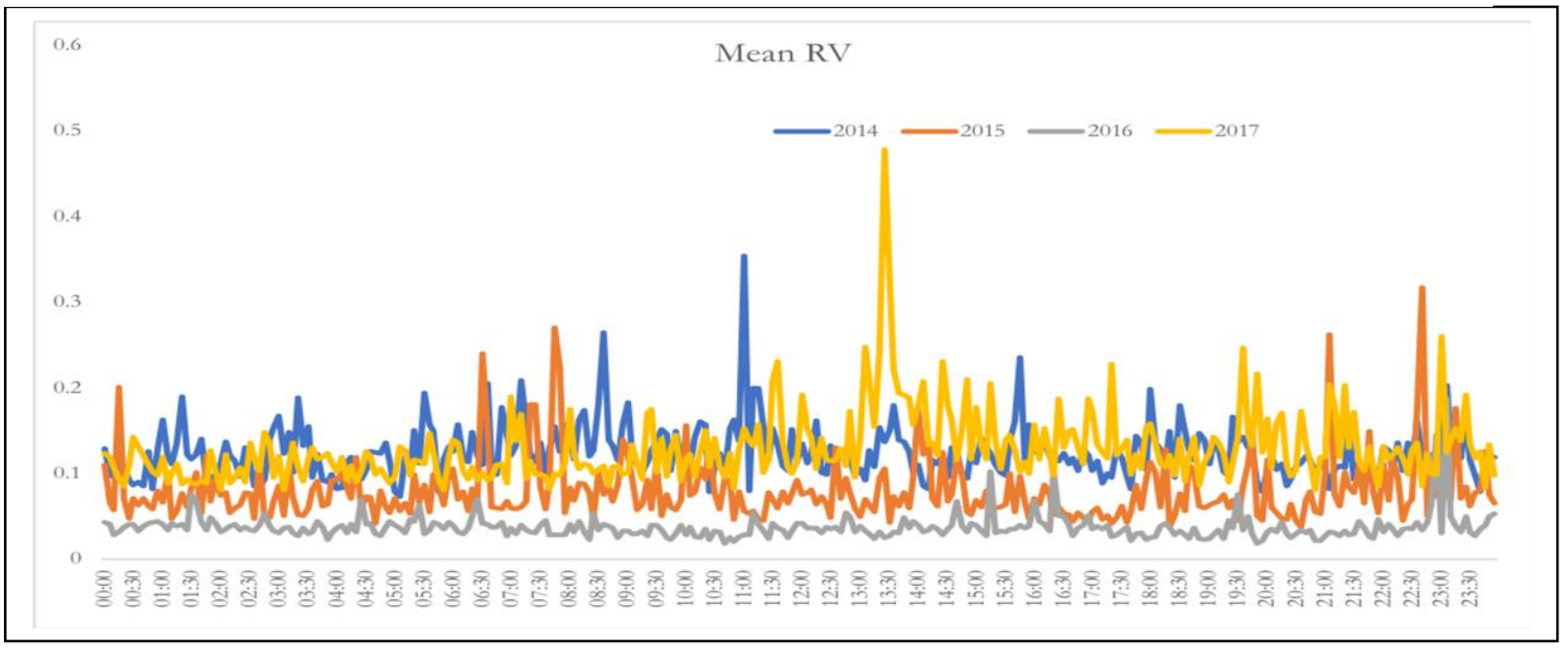

Figure 4: Intraday mean liquidity of Bitstamp over the four sample periods.

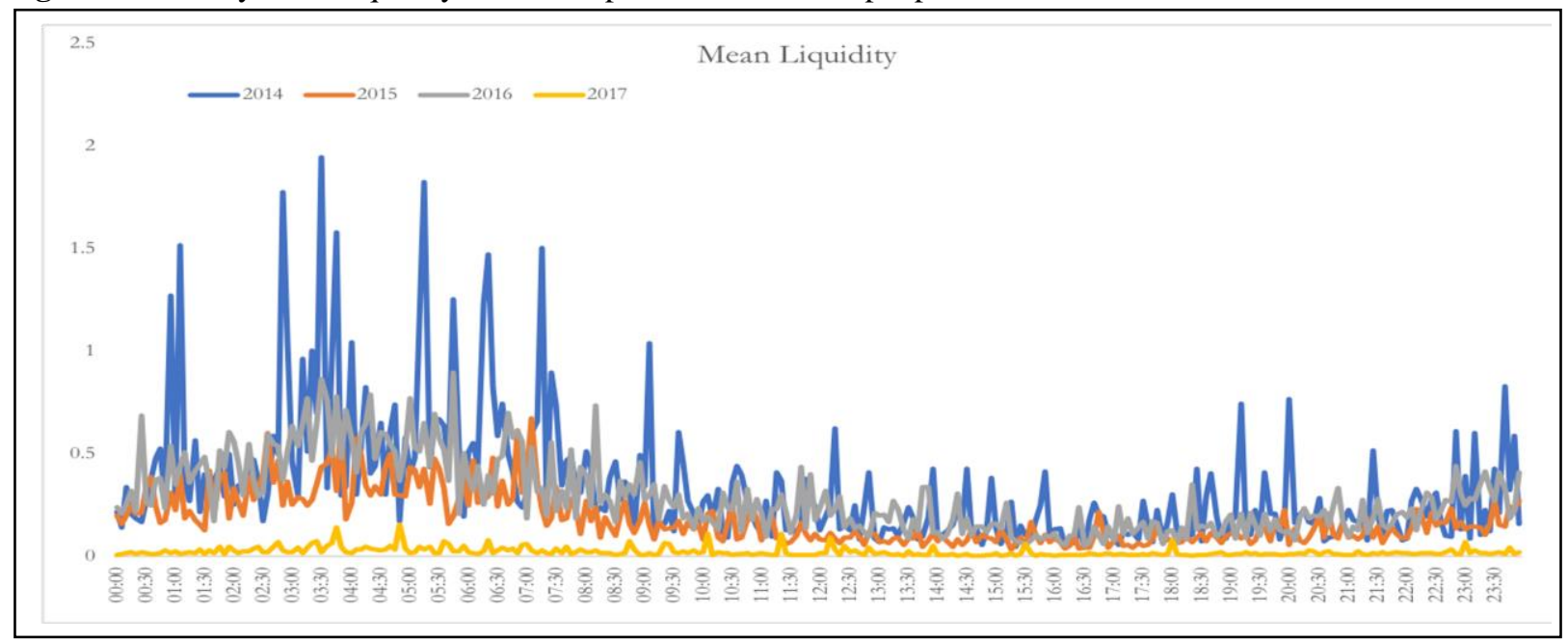


Figure 5: The cross-correlation between Bitcoin returns and volume over the four subsample periods for different lead and lag intervals.

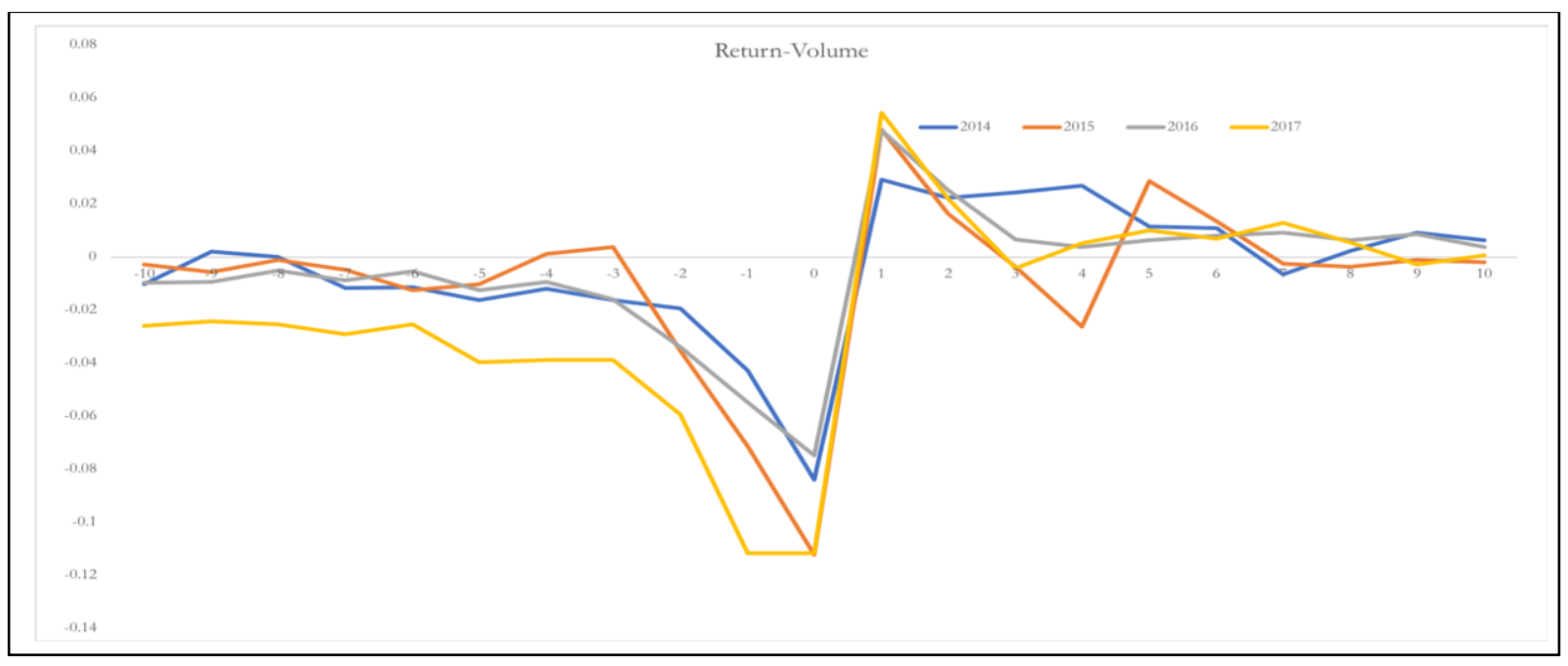

Figure 6: The cross-correlation between Bitcoin returns and RV over the four subsample periods for different lead and lag intervals.

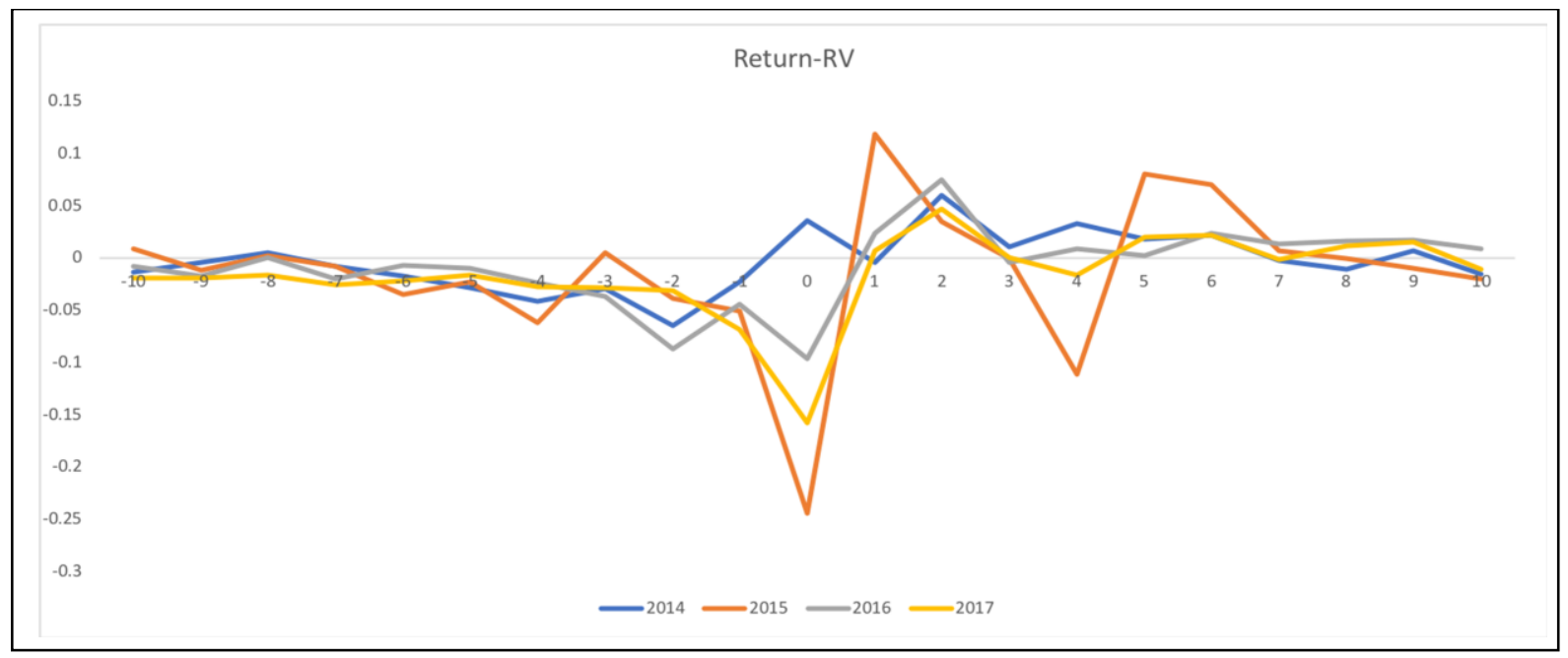

Figure 7: The cross-correlation between Bitcoin RV and volume over the four subsample periods for different lead and lag intervals.

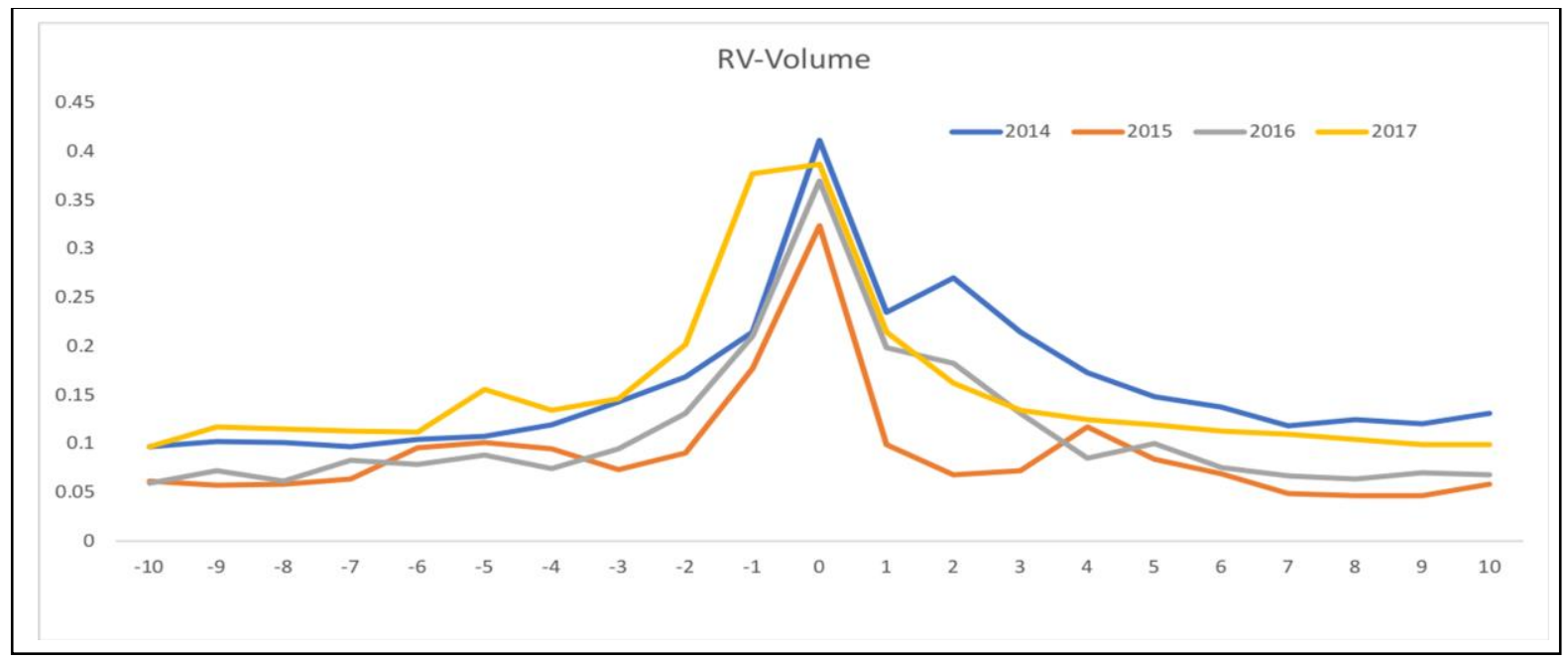


Figure 8: The cross-correlation between Bitcoin volume and liquidity over four subsample periods for different lead and lag intervals.

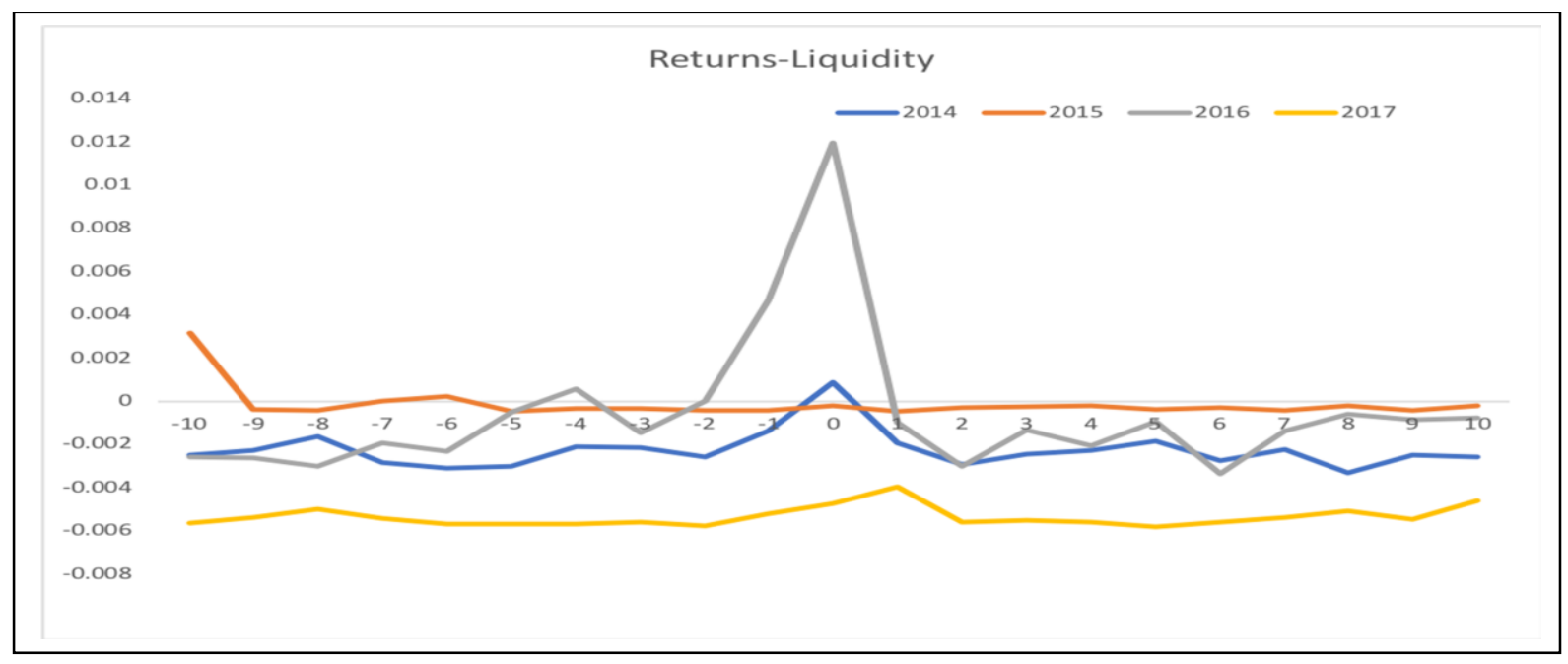

